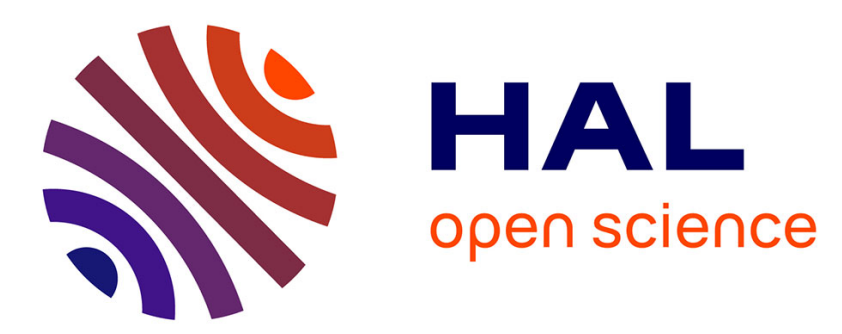

\title{
A NEW INJECTION LINE FOR THE TWO ECR SOURCES AT SARA
}

\author{
M. Fruneau, Ph. Martin, Sara Staff
}

\section{To cite this version:}

M. Fruneau, Ph. Martin, Sara Staff. A NEW INJECTION LINE FOR THE TWO ECR SOURCES AT SARA. Journal de Physique Colloques, 1989, 50 (C1), pp.C1-767-C1-771. 10.1051/jphyscol:1989181 . jpa-00229382

\section{HAL Id: jpa-00229382 https://hal.science/jpa-00229382}

Submitted on 1 Jan 1989

HAL is a multi-disciplinary open access archive for the deposit and dissemination of scientific research documents, whether they are published or not. The documents may come from teaching and research institutions in France or abroad, or from public or private research centers.
L'archive ouverte pluridisciplinaire HAL, est destinée au dépôt et à la diffusion de documents scientifiques de niveau recherche, publiés ou non, émanant des établissements d'enseignement et de recherche français ou étrangers, des laboratoires publics ou privés. 
JOURNAL DE PHYSIQUE

Colloque $\mathrm{Cl}$, supplément au $\mathrm{n}^{\circ} 1$, Tome 50 , janvier 1989

A NEW INJECTION LINE FOR THE TWO ECR SOURCES AT SARA

M. FRUNEAU, Ph. MARTIN and SARA STAFF

Institut des Sciences Nucléaires, Université Joseph Fourier, CNRS IN2P3, 53, avenue des Martyrs, F-38026 Grenoble cedex, France

\begin{abstract}
Résuimé
Une nouvelle vole d'injection pour deux sources ECR est en construction à SARA. Le faisceau délivré par MINIMAFIOS ou FERROMAFIOS est transporté sur une distance de $18 \mathrm{~m}$ jusqu'à l'inflecteur au centre du cyclotron injecteur. La voie comporte un canal électrostatique de $11 \mathrm{~m}$ de longueur. Les calculs d'optique et les résultats de mesures d'émittance de FERROMAFIOS sont présentés.
\end{abstract}

\begin{abstract}
A new injection line for two ECR sources is under construction at SARA. The beam delivered by MINIMAFIOS or FERROMAFIOS has to be transported down to the inflector at the center of the injector cyclotron over a distance of 18 meters. The line includes a $11 \mathrm{~m}$ long electrostatic channel. Beam optics calculations and first results of emittance measurements of FERROMAFIOS are presented.
\end{abstract}

An ECR source MINIMAFIOS (1) has been in operation at SARA since the end of 1983. Its high performances máde clear the need for a second one for two major reasons :

- New sources are constantly under development, with better yields, especially for "solid" ions and heavier elements and development is very difficult with one source only because of its continuous operation if coupled to a cyclotron.

- Running with metallic ions must be followed by the cleaning of the source chamber. Moreover, ECR sources keep the memory of ions for some time. When changing ion, it may therefore be desirable to operate the source for a certain time before injecting into SARA again, particularly if the new required ion has the same $\mathrm{q} / \mathrm{m}$ as that previously produced.

It was decided to install MINIMAFIOS and a source of the FERROMAFIOS type built by $R$. Geller and his team outside the cyclotron vault so as to run one source while working at the other. Both sources will be located in an existing room, the total beam line length to the median plane of the cyclotron will be $18 \mathrm{~m}$.

\title{
GENERAL LAYOUT OF THE BEAM LINE
}

The general layout of the injection beam line (2) is shown on figure 1 and the profile of the beam on figure 2. The two sources can be connected either to a very short line for analysis and development or to the injection line, via a symmetrical device. After the common magnet DIA2, DIA3 bends the beam downwards by $7.6 \mathrm{deg}$. into the electrostatic section through the $3 \mathrm{~m}$ concrete wall of the cyclotron vault. Subsequently, the beam is bent back to the horizontal plane, and after a new electrostatic section is deflected by two $45 \mathrm{deg}$. magnets to reach the existing axial injection beginning at the bunching close to the cyclotron yoke and ending at the pseudo-cylindrical inflector in the median plane of the accelerator (3). 


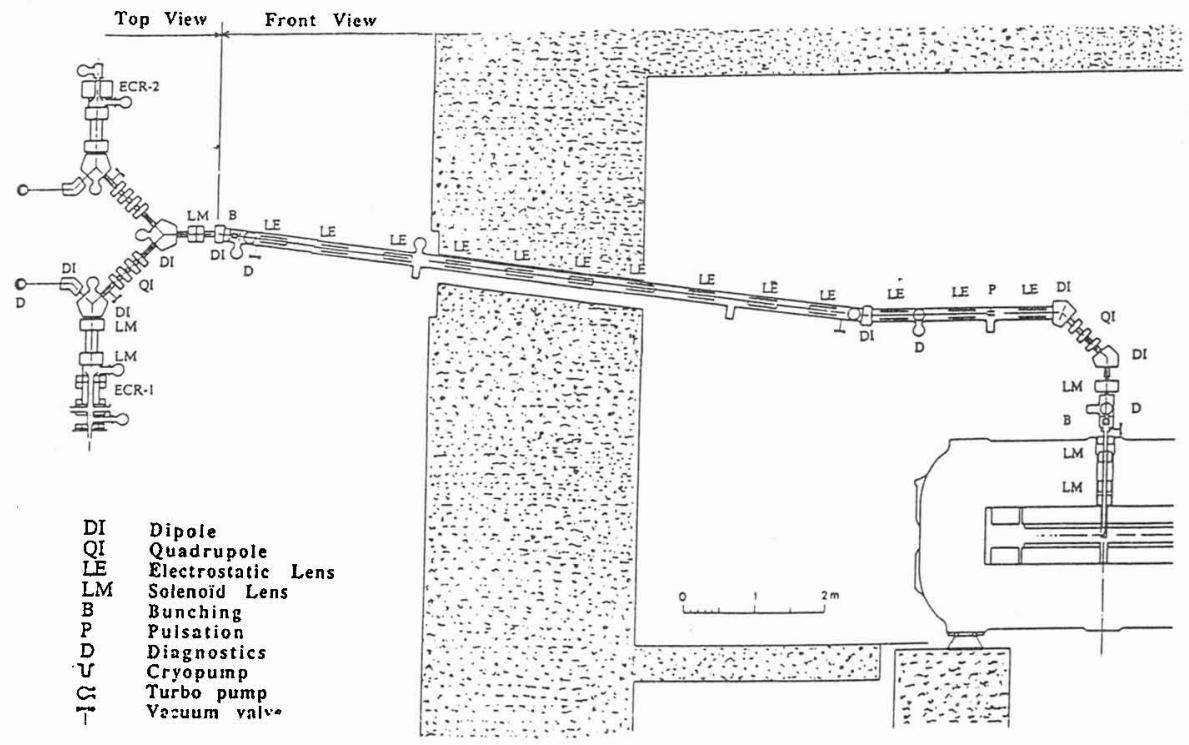

Figure 1 : Layout of the beam line.

\section{VACCUUM REgUIREMENTS}

Since the modification of the center of the injector cyclotron (4), the energy range extends from $2 \mathrm{MeV} / \mathrm{u}(\mathrm{h}=3)$ to $15 \mathrm{MeV} / \mathrm{u}(\mathrm{h}=2)$ leading to an energy of 10 to $40 \mathrm{MeV} / \mathrm{u}$ after the second cyclotron. The energy of the ions in the axial injection is 1.3 to $9.75 \mathrm{keV} /$ nucleon with accelerating voltages of 8 to $20 \mathrm{kV}$, the lowest $\mathrm{q} / \mathrm{m}$ value being 0.15. In this range of energies, the charge exchange cross sections are important $\left(17.10^{-15} \mathrm{~cm}^{2}\right.$ for $\left.\mathrm{Kr}^{15+}\right)$, leading to beam losses of $6 \%$ per meter at $10^{-6}$ torr ; to maintain the losses at $5 \%$ on the overall length, the mean pressure must not exceed 2.10-7 torr. This has led to a careful design of the vacuum system with turbomolecular pumps, and cryogenic pumps in the $10 \mathrm{~m}$ long electrostatic section. This latter part can be heated up to $150^{\circ} \mathrm{C}$ for outgassing.

\section{DESCRIPTION OF THE LINE}

First section : Extraction from the $8 \mathrm{~mm}$ diameter plasma hole of the source is made by a conical electrode ( $13 \mathrm{~mm}$ diameter) at an adjustable voltage so as to get the most constant conditions for the source extraction voltage. The extraction region must be ensured a very good vacuum and the ions encounter the first Glaser lens (LM1) after a $30 \mathrm{~cm}$ drift only. The two magnets and the four quadrupole lenses (QIAI to GLA4) have been designed as a symmetric optical system leading to achromatic and stigmatic transport $(5,6)$. A limited $q / m$ selection (about $1 / 18$ ) is achieved with the use of an analysing slit. Adaptation of the beam emittance to the acceptance of the electrostatic channel is adjusted via the magnetic lenses LM3-4 and LM1. At the end of this section, the beam is bent downwards by $7.6^{\circ}$ to reach the required hight above the cyclotron. The source can be best tuned beforehand by directing the beam through DAN which provides a better $\mathrm{q} / \mathrm{m}$ separation (about $2 \%$ ). The choice of Glaser lenses was dictated by their small aberrations leading to the possibility of a beam extension close to their inner dimensions, and the four quadrupoles were chosen to allow for room for the analysing slit. 


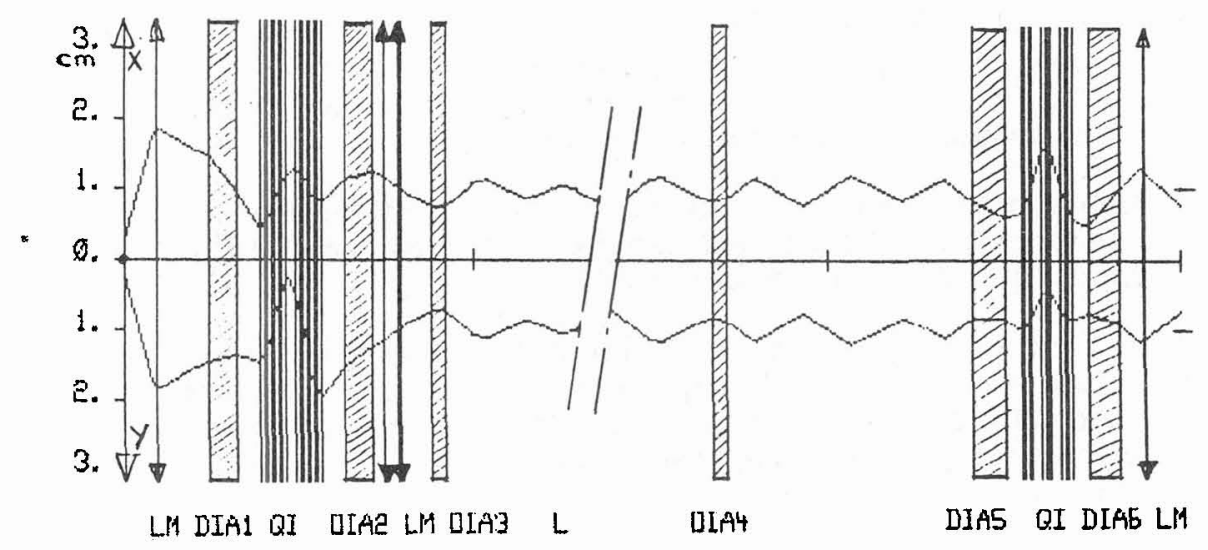

Figure 2 : Calculated beam profile

Electrostatic channel : Three solutions have been studied to transport the beam on this 11 meter long section: magnetic revolution lenses, magnetic quadrupoles of $50 \mathrm{~mm}$ diameter and cyclindrical electrostatic lenses in a $150 \mathrm{~mm}$ diameter tube. Results obtained previously in Grenoble (6) on the separator were in favour of the last solution with the following advantages : moderate cost, virtually zero power consumption, good vacuum particularly in the $3 \mathrm{~m}$ wall. The electrostatic solution was consequently adopted, in spite of technological difficulties.

This periodic system is composed of thirteen identical patterns, $860 \mathrm{~mm}$ long. Each pattern consists of 5 cyclindrical electrodes between two drift spaces (fig. 3). It ensures small variations of the beam envelope and a great stability relative to mismatching of the incoming beam and mistuning of the elements. It corresponds to 2.5 periods of oscillation. The applied negative voltage is about 1.1 the source voltage. Space charge effects can be accounted for by slightly increasing this voltage. The second vertical bending ( $7.6 \mathrm{deg}$.) occurs before the last 3 elements.

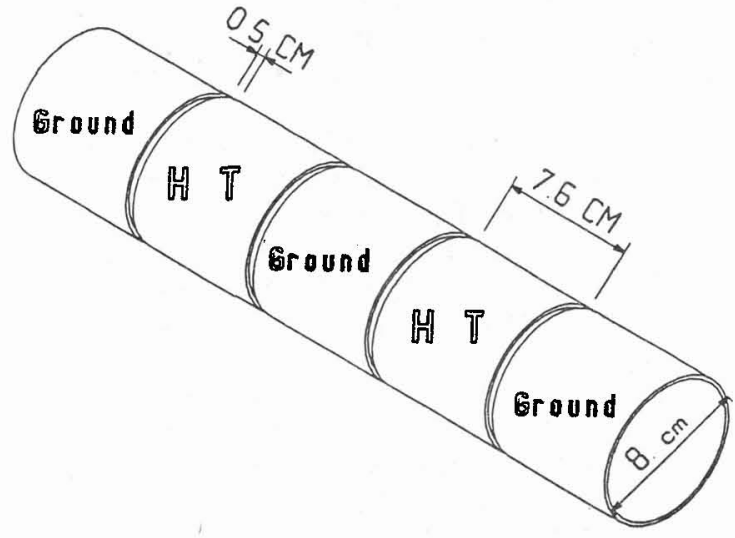

Figure 3 : One element of the electrostatic channel 
Vertical deflection and injection : Two $45 \mathrm{deg}$. magnets DIA5/6 and 3 quadrupoles QLA5 to 7 ensure quasi stigmatic and achromatic beam transport. LM5 is a modified Glaser lens (gap $=46 \mathrm{~mm}$, diameter $32 \mathrm{~mm}$ ). It provides a waist at the bunching, and the matching to the existing part of the axial injection (6).

Diagnostics : Mobile profile monitors of 16 horizontal and 16 vertical wires together with Faraday cups are placed at critical locations : the entrance and the exit of the electrostatic sections, and the entrance of the yoke.

Pulsation : The minimum duration of "Beam on" or "beam off "times is about $500 \mathrm{~ns}(7)$. This task is carried out by applying a square pulse between two plates - $120 \mathrm{~mm}$ long and $20 \mathrm{~mm}$ apart - located just before the last electrostatic element. The deflected beam is rejected by a diaphragm inside DIA5. A 250 Volt amplitude is sufficient at the highest source voltage.

Bunching : The existing two-gap cylindrical buncher works on the fundamental frequency of the $R F(8)$. It introduces a momentum dispersion $\Delta p / p \# 10^{-2}$ and provides a gain of 5 in the extracted beam intensity. In order to inject more of the available beam into the cyclotron (about $220 \mathrm{deg}$. out of $360 \mathrm{deg}$. RF phase still lost so far), it is attempted to pre-bunch the ions very early on the line, with a dispersion as small as $10^{-} 3$. The idea is to apply a very short pulse - 3 ns wide - up to 100 Volt amplitude at the $R F$ repetition rate, to a cyclindrical electrode. The gaps on either side are large compared to the distance covered by the ions during the pulse so that nearly all particles in each gap get the same acceleration or deceleration. They are expected to join together with unaffected ions about 10 meters downstream, precisely at the location of the main buncher. An additionnel gain in intensity between 1.5 and 2 is expected.

\section{PRELIMINARY RESULTS}

Emittance of the FERROMAFIOS source : The whole injection line was designed to accept an emittance area $A=150 \pi \mathrm{mm} . \mathrm{mrad}$. after measurements on MINIMAFIOS with $\mathrm{x}_{M}=\mathrm{y}_{M}=3 \mathrm{~mm}$ and $\mathrm{x}_{M}^{\prime}=\mathrm{y}_{M}^{\prime}=50 \mathrm{mrad}$. for an upright ellipse about the plasma hole. Consequently, a Glaser lens was fitted as close to the source as possible in order to transport $100 \%$ of the available beam. It was followed by a $45 \mathrm{deg}$. magnet to achieve a rough $\mathrm{q} / \mathrm{m}$ separation. The vertical and horizontal emittances, measured under these conditions are roughly consistent with the basic assumptions. In a subsequent step, the extraction setup was modified to protect insulating parts more efficiently and pumping speed was greatly improved in this zone.

Emittance shapes seem to depend strongly on the working conditions of the source and very large aberrations may show up. Fortunately, rather constant shapes can be obtained in the mean range of operation of the cyclotron with a very low gas flow and a fairly high microwave power. The voltage applied to the extraction electrode has to be increased considerably, say from 2 to $8 \mathrm{kV}$, when the source voltage is set below $10 \mathrm{kV}$. The strength of the first magnetic lens (LM1) is adjusted accordingly.

Beam line : One is supposed to match a stigmatic beam after DLA2 and LM34 to the admittance of the electrostatic channel. Recent measurements led to quadrupole excitations noticeably different from calculated values, implying the presence of a parasitic quadrupole effect on the line, still unidentified. It could be due for example to asymetric space charge effects, insufficient vacuum in the early stage, unexpected charge of insulating parts... Although not very critical, this problem is going to be dealt with. Most of the time and especially when out of focus, a rather large hole was 
observed on the axis in the beam emittance, depending strongly on the tuning of the source.

The beam has been fed through the electrostatic channel. A transmission of 90 to $100 \%$ and a stigmatic transport have been observed. It must be noted that the emittance measured at the exit was drastically disturbed as well as the beam spot location when the upstream profile monitor was put across the beam. Secondary electrons trapped in the well of the ion beam, local perturbation of the vacuum...? Some undesirable steering effect was also observed through this channel. The hypothesis of a space charge effect due to asymetry of the grounded walls around the beam axis is under examination.

\section{CONCLUSION}

The new injection line will be finally connected to the cyclotron at the end of 1988 . Despite the drawbacks described above, the ion beam extracted from the ECR source is expected to be injected into the cyclotron and accelerated with a high efficiency. The MINIMAFIOS source presently on the top of the yoke will be moved into the new source room. The main problems still under consideration at the moment are how to improve the source emittance and how to get the highest intensities out ouf the source for highly charged ions such as $\mathrm{Ar}^{12+}$ or metallic ions.

\section{References}

(1) See for instance, R. Geller, B. Jacquot, P. Sortais, Nucl. Instr. and Meth. A243 (1968) p. 244-254.

(2) M. Lieuvin, Internal report 86 I.S.N.

(3) J.L. Belmont and J.L. Pabot, IEEE Trans. NS-13, 191 (1966).

(4) S. Albrand, J.L. Belmont, M. Fruneau, A. Khallouf, Proc. $11^{\text {th }}$ Int. Conf. on Cyclotrons and their applications, Tokyo, 1987, p. 191.

(5) J.L. Belmont, $4^{\text {th }}$ International Conference on ECR sources (1982) p. 11-1.

(6) J.L. Belmont, Lecture notes of RCNP Kikuchi Summer School on Accelerator Technology, OSAKA, Japan, October 20-23, 1986, p. 7.9.

(7) J. Belmont, W. Joho, Design Note TRIUMF TRI-DN-73-16.

(8) J.L. Belmont, J.M. Bois, J. Hannelais, J.M. Lavrard, A. Longchamp, J.L. Salmon, Internal Report RI2-1970 - I.S.N. GRENOBLE. 